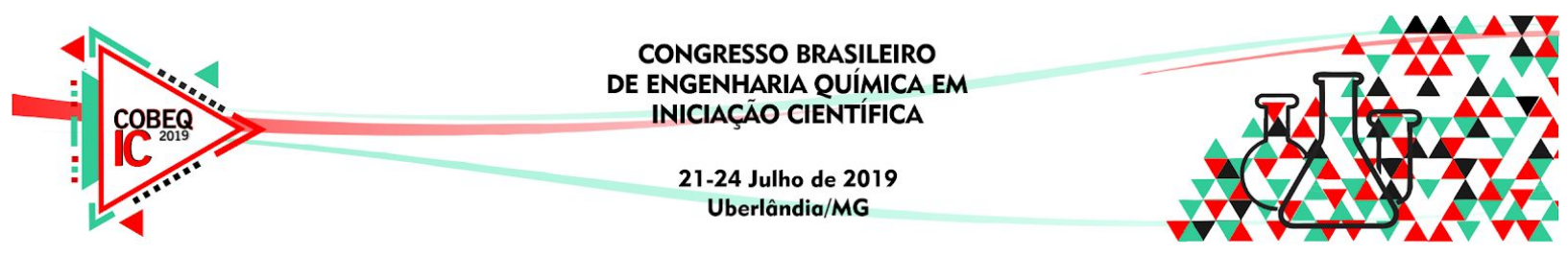

\title{
GERENCIAMENTO DOS RESÍDUOS SÓLIDOS EM ESCOLAS DA REDE ESTADUAL DE NATAL-RN E O IMPACTO NA SAÚDE PÚBLICA LOCAL
}

\author{
C.R.B. ARAÚJO ${ }^{1}$, G. N. A. LIMA ${ }^{1}$,I. V. O. LEITE ${ }^{1}$, L.L.C. LEITE ${ }^{1}$, T. J. LUCKWU1 \\ ${ }^{1}$ Universidade Federal do Rio Grande do Norte, Faculdade de Engenharia Química \\ E-mail para contato: carolrayanne@gmail.com - nayanneandradenayanne@gmail.com - \\ izaleite11@hotmail.com - leonaraluizza@hotmail.com - thamy.lucksilva@hotmail.com
}

RESUMO - O descarte inadequado de resíduos sólidos, além de poluir e degradar o meio ambiente, é uma questão de saúde pública. A partir disso, vê-se que a falta de gerenciamento dos resíduos sólidos é um agravante de doenças causadas por vetores, que encontram nesses resíduos um meio para proliferação. A fim de solucionar tais problemas implementou-se a lei 12.305/10 de Política Nacional de Resíduos Sólidos (PNRS) que estabelece diretrizes para a gestão desses resíduos. Neste trabalho, foi analisada a relação entre as principais doenças das comunidades e o gerenciamento dos resíduos sólidos de 16 escolas estaduais de Natal-RN. Os dados coletados mostram que apesar do gerenciamento inadequado de resíduos sólidos nas escolas contribuir para um aumento na taxa de doenças nas comunidades, a maior contribuição está nos resíduos gerados pela própria comunidade, fora da escola.

\section{INTRODUÇÃO}

Com o atual crescimento populacional e industrial, uma das grandes preocupações da humanidade é a geração de resíduos sólidos. De acordo com a lei 12.305/10 - Política Nacional de Resíduos Sólidos (PNRS) - resíduo sólido é um material ou substância descartado resultante de atividades humanas, cuja destinação final se procede nos estados sólido ou semissólido, bem como gases contidos em recipientes e líquidos cujas particularidades tornem inviável o seu lançamento na rede pública de esgotos ou em corpos d'água, ou exijam para isso soluções técnica ou economicamente inviáveis em face da melhor tecnologia disponível (Brasil, 2010).

Esses resíduos apresentam-se como um dos principais problemas nas áreas urbanas, pois sua geração, descarte e disposição inadequados provocam diversos impactos ambientais, sociais, econômicos e de saúde pública (Gonçalves et al., 2010). Em relação à saúde pública, os resíduos sólidos destacam-se na linha de transmissão de doenças provocadas pela ação dos vetores, que encontram no habitat do lixo condições adequadas para a sua proliferação (Siqueira; Morais, 2009). 


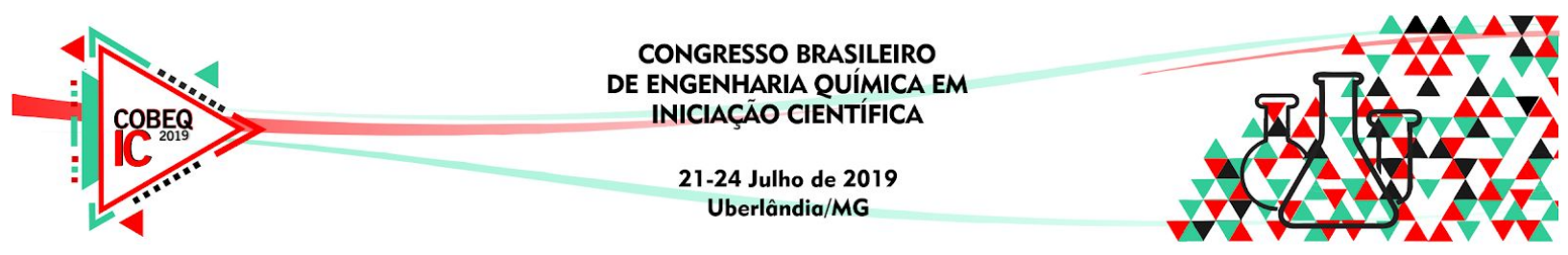

Sendo assim, a fim de organizar a forma com que o país lida com o lixo e exigir dos setores públicos e privados transparência no gerenciamento de seus resíduos, a PNRS estabelece princípios, objetivos, instrumentos e diretrizes para a gestão integrada e gerenciamento dos resíduos sólidos, indicando as responsabilidades dos geradores, do poder público, e dos consumidores (Brasil, 2010). A lei 12.305/10 também exige que haja um Plano de Gerenciamento de Resíduos Sólidos (PGRS), desde o âmbito nacional ao municipal. A finalidade do PGRS é contribuir para a redução da geração de resíduos sólidos, orientando o correto acondicionamento, armazenamento, coleta, transporte, tratamento e destinação final. Esse documento deve mostrar e descrever ações relativas ao manejo de resíduos sólidos e conter a estratégia geral dos responsáveis pela geração dos resíduos para proteger a saúde humana e o meio ambiente (Gonçalves et al., 2010).

Neste trabalho foi feito um levantamento sobre o gerenciamento dos resíduos sólidos em escolas estaduais de Natal-RN, tais escolas foram escolhidas de acordo com o grau de vulnerabilidade social. Ao coletar os dados, viu-se que a saúde da população estava sendo comprometida devido às doenças transmitidas por vetores que se proliferam em ambientes contendo lixo.

\section{OBJETIVO GERAL}

Avaliar a relação entre o gerenciamento de resíduos sólidos e a saúde pública local.

\subsection{Objetivos específicos}

- Relacionar os resíduos gerados com a ocorrência de dengue na região;

- Relacionar os resíduos gerados com a incidência de sintomas gerais como cefaléia, diarréia, vômito;

- Traçar um perfil de acondicionamento de resíduos sólidos em cada escola.

\section{METODOLOGIA}

Foi utilizado o método de pesquisa de campo com a finalidade de coletar dados e informações diretamente da realidade do objeto de estudo. O processo de coletar esses dados se deu através do deslocamento até as escolas pré-selecionadas. Essa seleção foi feita com base em dados socioeconômicos de cada região, tendo como prioridade escolas em regiões mais carentes. Os dados foram obtidos por meio de questionários socioeducativos aplicados com alunos e funcionários das 16 escolas abrangidas. A finalidade é traçar um perfil que possa ser trabalhado como exemplo e aplicado junto aos objetos empíricos.

O estudo tem caráter essencialmente qualitativo, com ênfase na observação e estudo de análise de dados, ao mesmo tempo que será necessário o cruzamento dos levantamentos com toda a pesquisa bibliográfica já feita. 


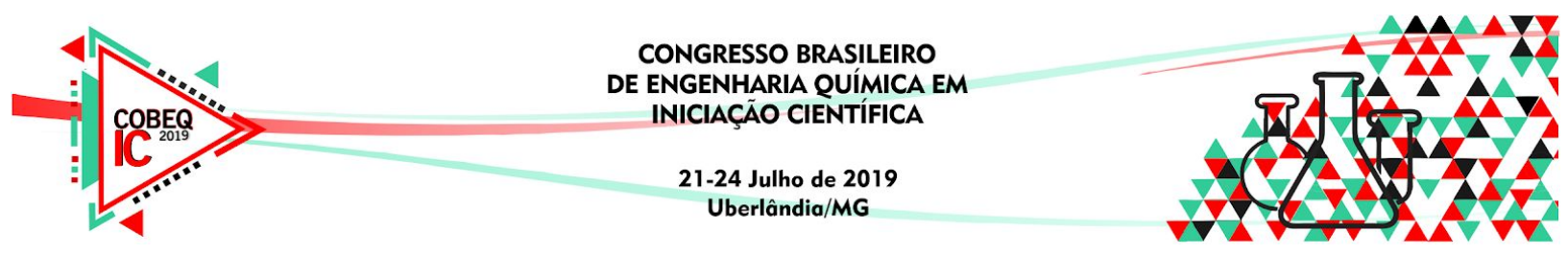

\section{RESULTADOS E DISCUSSÕES}

\subsection{Quanto à geração de resíduos nas escolas}

Quando perguntados os lugares de maior geração de resíduos na instituição, os três pontos mais citados foram: sala de aula, pátio e nos arredores da escola (figura 1). Vale salientar que esta pergunta era de múltipla escolha e ainda assim constatou-se que, nas escolas da Zona Oeste há uma acentuada produção de resíduos no pátio e em volta da escola. Nas escolas da Zona Norte, as salas de aula e as cantinas também se apresentam como potenciais geradoras de resíduos.

Figura 1. Gráfico dos dados referentes aos locais de maior geração de resíduos.

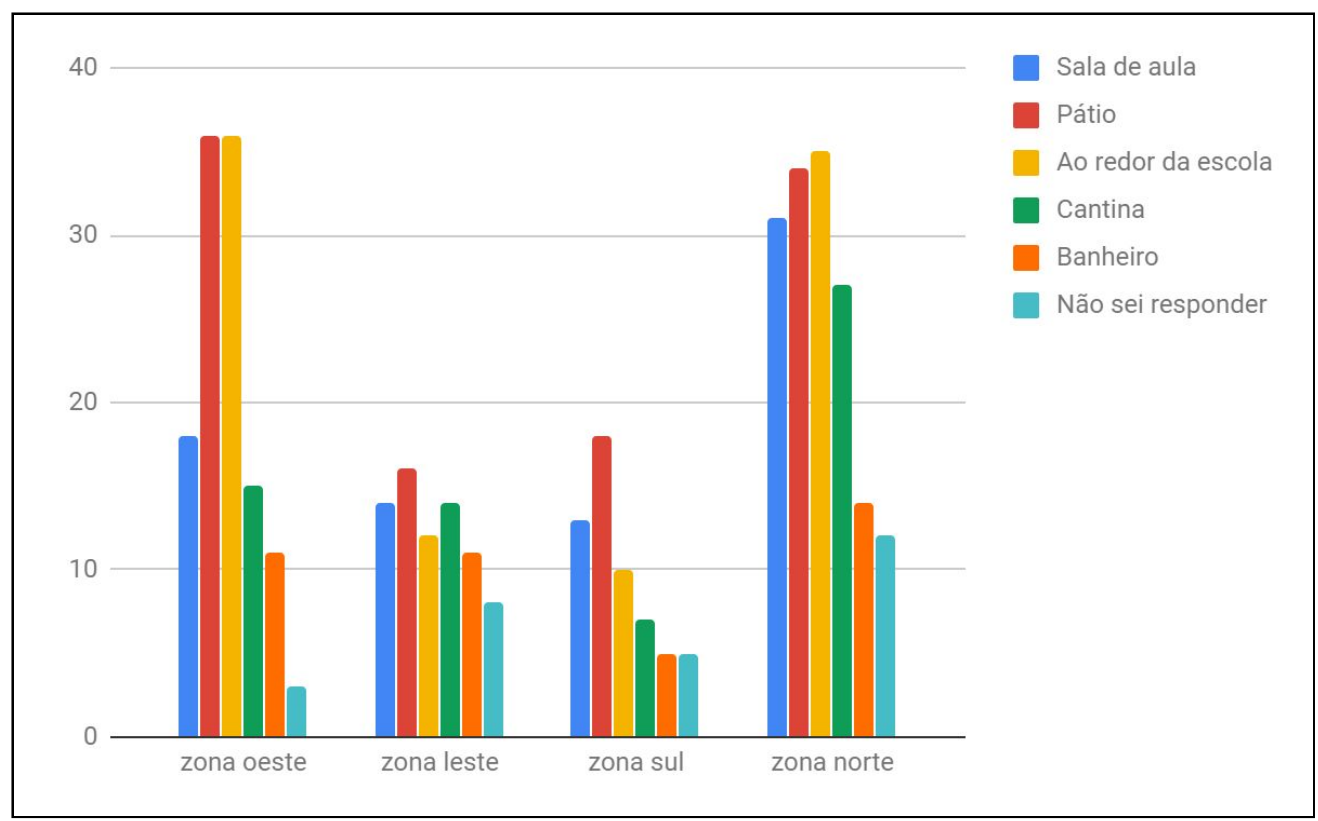

Quanto ao acondicionamento (figura 2), percebeu-se que as escolas da Zona Oeste, são as únicas que apresentam um maior número de indicações para a separação e reciclagem dos resíduos gerados, enquanto que escolas das Zonas Leste e Norte apresentam maior número de indicações para o latão fechado e não separado. Já nas escolas da Zona Oeste, o que se observa é uma maior divergência de acondicionamento dos resíduos, apresentando um perfil quase uniforme entre a reciclagem, latas e sacos plásticos fechados.

Vale salientar que, na maioria das escolas visitadas, a coleta é de responsabilidade da prefeitura, sendo realizada até três vezes por semana, assim em dias de coleta os resíduos são acomodados ao ar livre, em frente às escolas. Dessa forma pessoas e animais que, diariamente, utilizam aquela rua como rota de percurso, se encontram expostas aos riscos oferecidos pelos resíduos. Atrelado a isso, em algumas escolas, pôde-se observar a presença de resíduos com água acumulada, o que é tomado como um potencial fator de risco, seja 


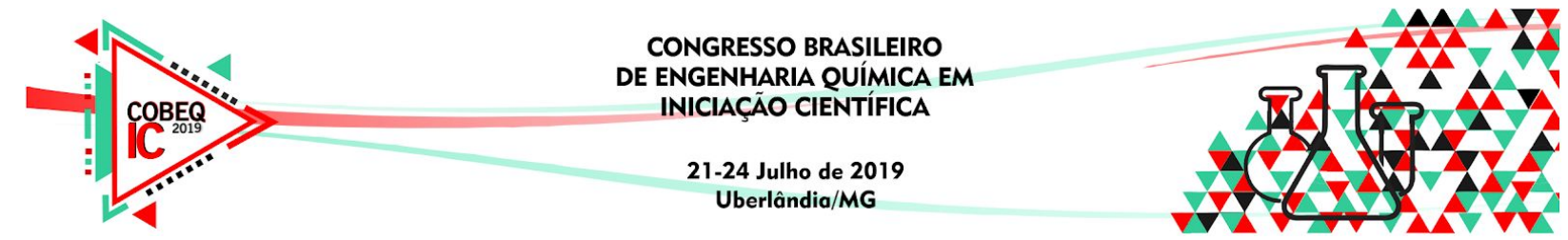

dentro ou nas vizinhanças da instituição, uma vez que servem de criadouro para focos do mosquito Aedes Aegypti.

Figura 2. Gráfico dos dados referentes aos tipos de "lixos" mais verificados nas escolas.

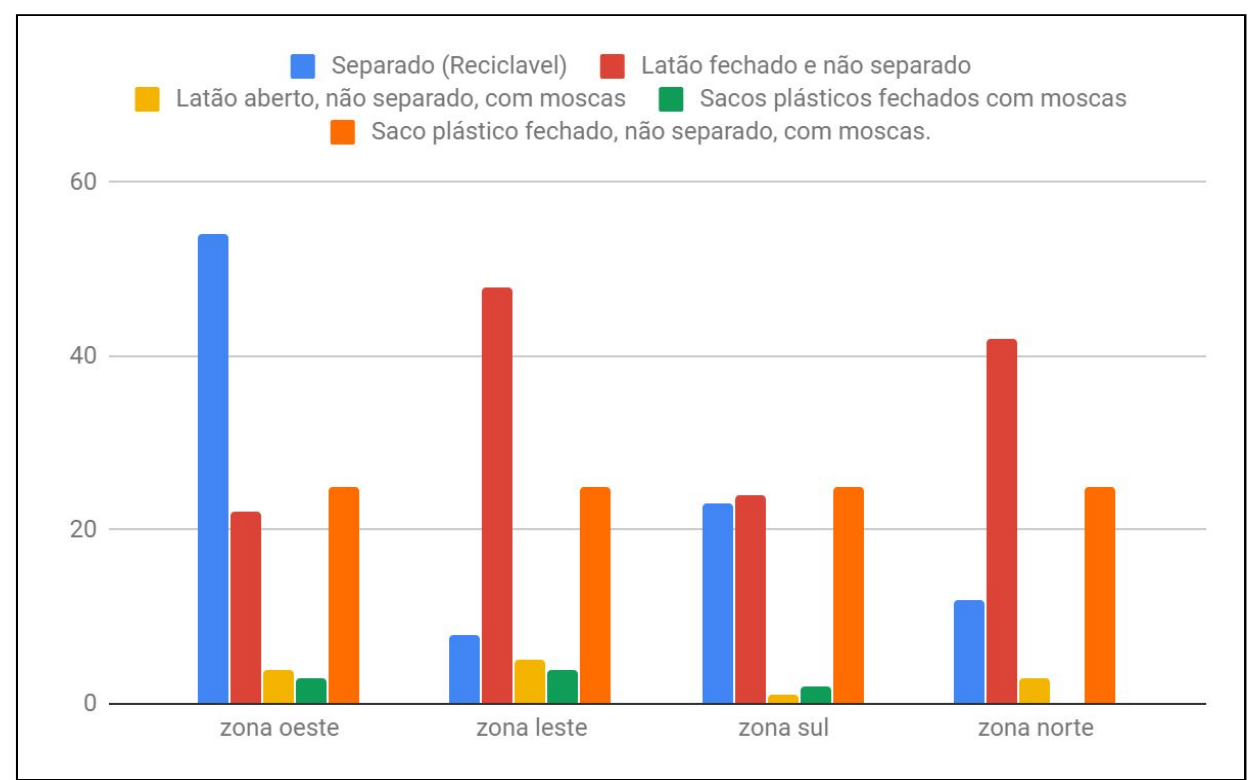

Como pode ser observado na figura 3, referente aos tipos de resíduos que podem acumular água, vemos que apenas nas instituições da Zona Oeste o número de dados obtidos para a alternativa "sim" ultrapassa a quantidade obtida para a alternativa "não".

Figura 3. Dados referente à pergunta: "Você encontra muitas garrafas, tampinhas, copos ou vasilhas com água da chuva na sua escola?".

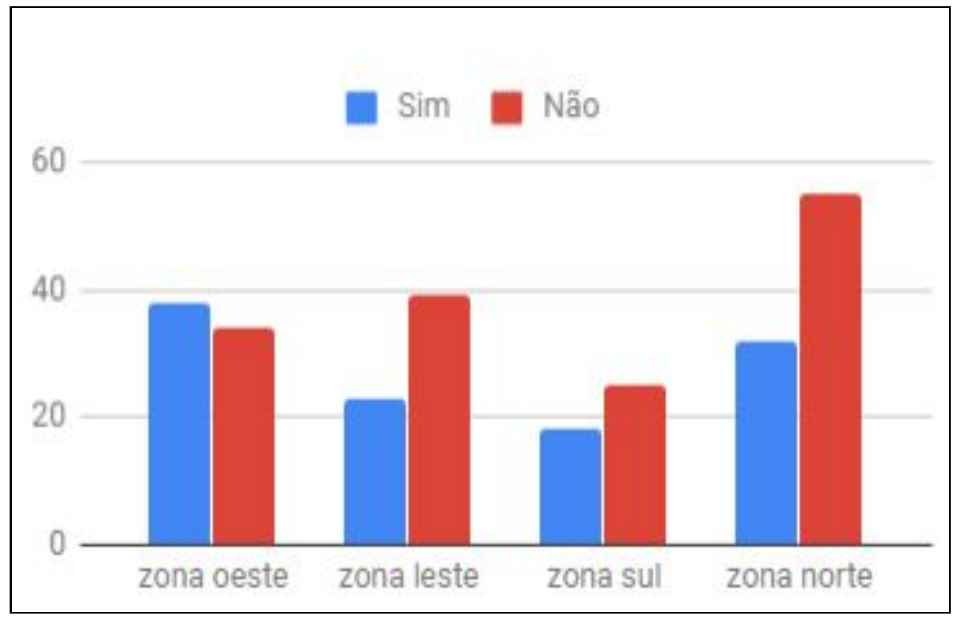

\subsection{Quanto à vizinhança e a saúde pública local}




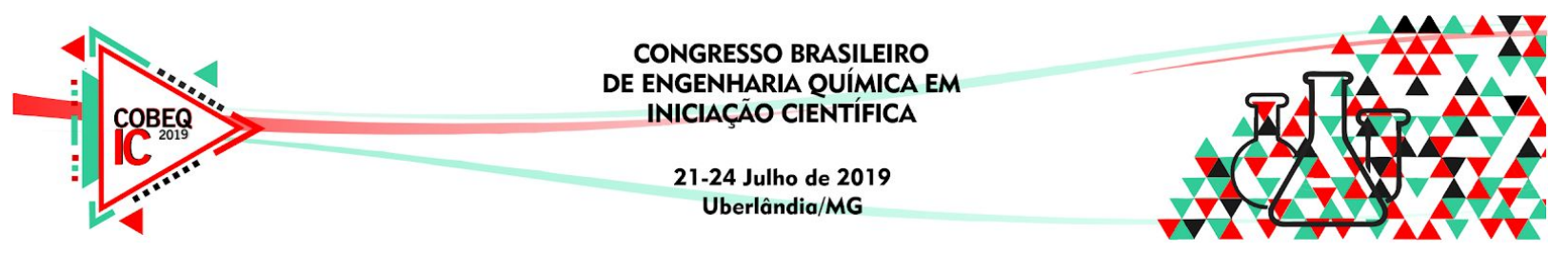

No que diz respeito à saúde pública local, foram realizadas duas vias de análise de dados, uma direcionada à ocorrência de casos de dengue nas vizinhanças das escolas, e outra voltada para sintomas em gerais. Fez-se necessário essa divisão, uma vez que o fato das escolas possuírem em seus espaços, potenciais criadouros de focos do mosquito Aedes Aegypti, pode estar diretamente relacionado com a incidência de casos de dengue nas comunidades em que estão situadas.

Quando perguntados quanto à dengue, é possível verificar na figura 4 que a Zona Norte foi a zona que mais apresentou casos da doença, seguida respectivamente das zonas Leste, Oeste e Sul. Comparando o gráfico da figura 4 ao gráfico da figura 3, constata-se que não há relação direta entre os resíduos com água acumulada encontrados nas dependências das escolas e a ocorrência de casos de dengue nas comunidades, uma vez que a Zona Norte apresentou menor porcentagem de resíduos e maior casos de ocorrência da doença, ainda sim, este elevado índice pode estar relacionado com as condições de saneamento básico e coleta de lixo em pontos próximos às escolas.

Figura 4. Dados referente à pergunta: "Você ou alguém da sua casa já teve dengue?”.

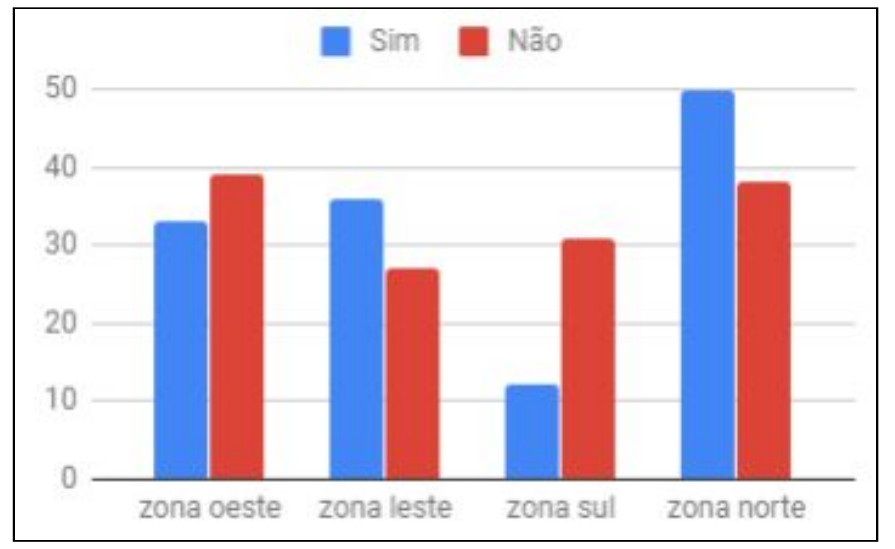

No gráfico da Figura 5 observa-se um comportamento similar ao anterior, no entanto a comparação deste se dá em relação ao acondicionamento dos resíduos nos dias de coleta, isto é, como a exposição do "lixo" impacta a saúde dos moradores daquela região. Novamente, vale salientar que esta era uma pergunta de múltipla escolha. Logo, comparando este gráfíco com o gráfico da figura 2, vemos que a Zona Norte apresentou inúmeras ocorrências para os sintomas citados, de forma que o tipo de tratamento dado aos resíduos (latão fechado e não separado), pode ter relação direta com o fato. Já a Zona Oeste, por mais que tenha apresentado com maior frequência o acondicionamento baseado na separação e reciclagem, apresentou também altos índices das ocorrências dos sintomas, neste caso, a responsabilidade da escola quanto ao "lixo" e a ocorrência dos sintomas é mínima ou irrelevante.

Figura 5. Dados referente à pergunta: "Nas últimas semanas, você ou alguém da sua casa apresentou os seguintes sintomas?". 

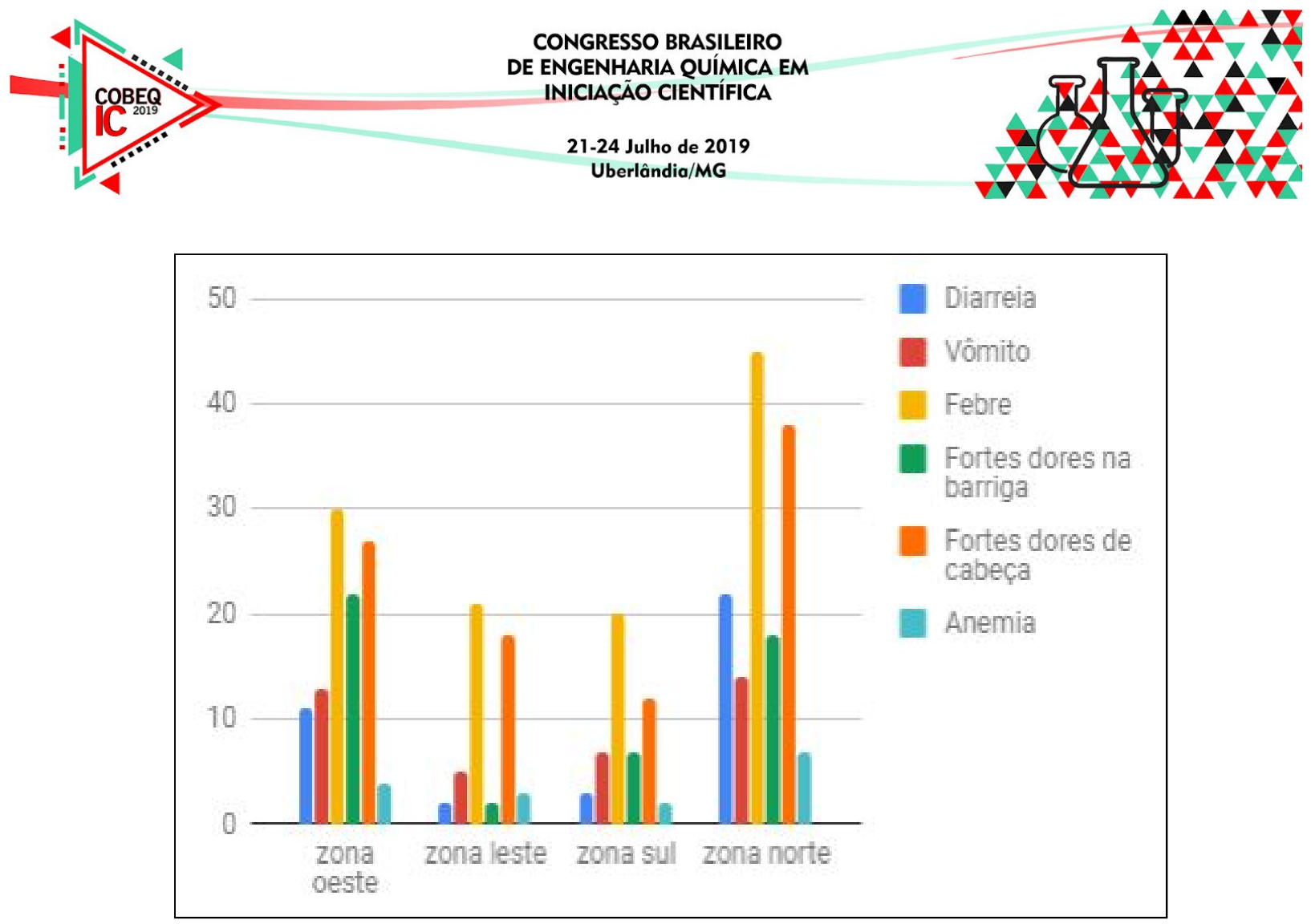

\section{CONCLUSÃO}

A pesquisa realizada constatou que apesar do descarte inadequado de resíduos sólidos nas escolas contribuir para um aumento na taxa de doenças nas comunidades, a maior contribuição está nos resíduos gerados pela própria comunidade, fora da escola. Também observou-se que o número de casos de dengue na zona Norte era maior que nas outras regiões, entretanto, o questionário aponta a zona Oeste com maior casos de água armazenada em locais propícios para a proliferação do mosquito Aedes Aegypti, indicando incerteza quanto a correlação dos casos com a falta de prevenção da escola, deve-se também considerar fatores externos como, por exemplo, a existência de criadouros fora da instituição de ensino, o que poderia ser a causa da quantidade de casos de dengue na região Norte ser maior que as demais.

\section{REFERÊNCIAS}

GONÇALVES, Morgana Suszek. Gerenciamento de resíduos sólidos na Universidade Tecnológica Federal do Paraná Campus Francisco Beltrão. Revista Brasileira de Ciências Ambientais-Número, p. 80, 2010.

BRASIL. Lei $\mathrm{n}^{\mathrm{o}}$ 12.305, de 02 de agosto de 2010. Política Nacional de Resíduos Sólidos. Diário Oficial da União, Brasília, 02 ago. 2010.

SIQUEIRA, Mônica Maria; MORAES, Maria Silvia de. Saúde coletiva, resíduos sólidos urbanos e os catadores de lixo. Ciência \& Saúde Coletiva, v. 14, p. 2115-2122, 2009. 